\title{
Quantitative effects of tobacco smoking exposure on the maternal-fetal circulation
}

\author{
Julia de B Machado ${ }^{1 * \dagger}$, Plínio VM Filho ${ }^{1 \dagger}$, Guilherme O Petersen ${ }^{2 \dagger}$ and José M Chatkin ${ }^{3 \dagger}$
}

\begin{abstract}
Background: Despite the existence of various published studies regarding the effects of tobacco smoking on pregnancy, and especially in regards to placental blood flow and vascular resistance, some points still require clarification. In addition, the amount of damage due to tobacco smoking exposure that occurs has not been quantified by objective means. In this study, we looked for a possible association between flow resistance indices of several arteries and the levels of urinary cotinine and the concentration of carbon monoxide in the exhaled air (COex) of both smoking and non-smoking pregnant women. We also looked for a relationship between those findings and fetal growth and birth weight.
\end{abstract}

Methods: In a prospective design, thirty pregnant smokers and thirty-four pregnant non-smokers were studied. The volunteers signed consent forms, completed a self-applied questionnaire and were subjected to Doppler velocimetry. Tobacco smoking exposure was quantified by subject provided information and confirmed by the measurement of urinary cotinine levels and by the concentration of carbon monoxide in the exhaled air (COex). The weight of newborns was evaluated immediately after birth.

Results: Comparing smoking to non-smoking pregnant women, a significant increase in the resistance index was observed in the uterine arteries $(P=0.001)$ and umbilical artery $(P=0.001)$, and a decrease in the middle cerebral artery $(P=0.450)$. These findings were associated with progressively higher concentrations of COex and urinary cotinine. A decrease in the birth weight was also detected $(P<0.001)$ in association with a progressive increase in the tobacco exposure of the pregnant woman.

Conclusions: In pregnant women who smoke, higher arterial resistance indices and lower birth weights were observed, and these findings were associated with increasing levels of tobacco smoking exposure. The values were significantly different when compared to those found in non-smoking pregnant women. This study contributes to the findings that smoking damage during pregnancy is dose-dependent, as demonstrated by the objective methods for measuring tobacco smoking exposure.

\section{Background}

Evidence regarding the negative effects of tobacco smoking on fetal development is widely documented in existing literature. The toxic effects vary from perinatal complications, such as low birth weight, to changes in adult behavior [1-5].

Regarding the effects of maternal tobacco smoking on placental blood flow and vascular resistance, there still

\footnotetext{
* Correspondence: juliamachado@terra.com.br

† Contributed equally

'Obstetrics, Sao Lucas Hospital da Pontificia Universidade Catolica do Rio

Grande do Sul,of Rio Grande do Sul, Porto Alegre, Brazil
}

Full list of author information is available at the end of the article exists some controversy regarding which vessels are most affected and if the effects are acute or chronic [6].

However, most studies quantify smoking only by the self-report of subjects, a method that is frequently not reliable. It is known that smokers sometimes provide false information about their smoking status, and among pregnant women, the percentage of misreporting is unknown. This occurs especially if the individual is under pressure to quit smoking and thus a bias towards a socially desirable response may occur [7-9].

The prevalence of patients who state they are not smoking anymore when, in fact, they actually still do varies between $3 \%$ and 10\% [9,10]. Abstinence during smoking cessation treatment needs to be confirmed by

\section{Ciomed Central}


objective measurements and biochemical markers have been introduced in clinical practice $[9,10]$.

The carbon monoxide concentration in exhaled air (COex) is the most frequently used marker [10]. It is affordable and measured by a non invasive technique that provides immediate and reliable results [11]. It has been widely used at smoking cessation centers in most countries including Brazil [12-14].

The salivary, plasmatic and urinary cotinine concentrations are considered to be the golden standard for objective evidence, but measurements require expertise [9], are expensive and are not for clinical practice [15].

Doppler velocimetry in Obstetrics is used to measure blood flow in the uterine arteries, and it characterizes the blood flow from the mother to the fetus. When the blood flow is studied in the fetal middle cerebral artery, it shows the flow in fetal brain. There are tables with established values that are considered normal. The methodology has already been standardized and we have followed such guidelines in this study.

This study aimed to search for a relationship among resistance indices of the uterine, umbilical and middle cerebral fetal arteries via Doppler velocimetrical ultrasonographic evaluation and smoking habits measured through objective methods (cotinine concentration and COex). The relationship between smoking and fetal growth and with birth weight was also examined.

Our primary objective was to assess whether there is a proportional change in vascular resistance as quantitative exposure to smoking during pregnancy increases. The hypothesis is that smoking reduces the maternalfetal blood flow related to increased tobacco smoking and effects fetal growth.

\section{Methods}

Using a prospective cohort design study, 30 pregnant smokers and 34 pregnant non-smokers were recruited between September 2008 and September 2009 from the Low Risk Prenatal Care Center of the Obstetric Department at the Hospital Sao Lucas da Pontificia Universidade Catolica do Rio Grande do Sul (HSL-PUCRS) in Porto Alegre, Brazil.

The inclusion criteria were: pregnant women between 18 and 35 years of age, in the third trimester of gestation (dated in the first trimester), regularly receiving prenatal care, had no gestational complaints and agreed to participate in the study by signing the consent form. The exclusion criteria were: ultrasonographic diagnosis of fetal malformations, clinical situations related to the pregnancy or any other disease that could interfere with fetal growth, illiteracy, psychiatric disorders, alcoholism, former smokers and the possibility to move to another city and to lose contact during the study. Patients who discontinued prenatal care and those that stopped or started smoking during their pregnancy were also excluded. No patient was excluded after inclusion in the study because no patient discontinued the follow up during the prenatal period.

Smoking was determined according to the report of using cigarettes from the periconceptional period to the day of the interview. The periconceptional period was defined as the period starting one month before the date of the last menstruation. To be considered a nonsmoker, patients must have stated that they had never smoked, especially during their pregnancy, and reports were confirmed by a biochemical marker.

All patients were submitted to same tests to confirm their smoking status: concentration of carbon monoxide in the exhaled air and concentration of urinary cotinine. We found no discrepancy, that is, no patient who said was a non-smoker was detected as a smoker.

At the initial medical visit, the objectives of the study were explained and the consent form signature was obtained.

Next, a standardized questionnaire was completed, pregnancy and smoking data were collected and the COex measurement was performed. A urine sample was also collected to measure cotinine levels, and an ultrasonograph examination was performed. Smoking between the tests was not permitted. After the birth, patient was contacted to collect data about the newborn one month after delivery.

Doppler velocimetry exam with colored mapping of the uterine arteries, umbilical arteries and fetal medium cerebral arteries was performed with an Ultrasonix machine (Sonix Model, Version 2.5, Ultrasonix Medical Corporation, Canada), and the resistance indices (RI) were recorded. We also recorded the amniotic fluid index, the placental grade, fetal biometry and the estimated fetal weight placed on a percentile curve for the gestational age to adjust for possible bias.

To decrease possible bias at ultrasonography due to a large variability of Doppler values, three measurements were taken, and the mean was recorded.

COex was measured by a MicroCO Meter (MicroCO Micro Medical Ltd., Rochester, Kent, UK) using an electrochemical sensor. Patients were instructed to breathe deeply, hold their breath for 20 seconds and then to exhale slowly and completely through a mouthpiece. Smokers had COex measured no more than two hours after their last smoked cigarette [9].

For measurement of the cotinine concentration in the urine, a previously-validated high performance liquid chromatography (HPLC) method was used [16].

Whereas the ultrasonography examinations and the exhaled $\mathrm{CO}$ measurements were performed by the same 
author (JBDM), the cotinine measurements were performed at the PUCRS Toxicology Institute by a technician blind to patient study group.

Mean \pm SD were used to describe the symmetric, continuous data and the median and range was used for asymmetric data. A percentile calculation was used for categorical data. Student's t test and ANOVA were used to compare means. Adjustments for potential confounding effects were made by covariance analysis (ANCOVA) and multiple linear regression. Possible confounding factors included in the analysis for adjustment were patient age, gestational age, degree of placenta, amniotic fluid index, number of pregnancies. The assigned level of significance was 0.05 . The data were processed by the Statistical Package for the Social Sciences (SPSS) Version 17.0

Patients were divided into four groups according to the levels of COex (Group1: 0 ppm; Group 2: 1-4 ppm; Group 3: 5-9 ppm; Group 4: $\geq 10 \mathrm{ppm}$ ) in order to analyze possible changes in the resistance indices. The same analyses were also performed according to the levels of urinary cotinine (Group 1: $0 \mathrm{ng} / \mathrm{mL}$; Group 2: $<50 \mathrm{ng} / \mathrm{mL}$; Group 3: 50-500 ng/mL; Group $4>500 \mathrm{ng} / \mathrm{mL}$ ).

We used percentiles to compare the resistance indices and fetal birth weights according to the gestational age of each patient. For weight, a Hadlock table was used [17]. Analysis of the resistance index values was performed by using the published standards for the respective percentiles [17].

The study was approved by the PUCRS Research Ethics Committee, under No. 08/04319 on May $09^{\text {th }} 2008$.

\section{Results}

Thirty pregnant smokers and 34 pregnant non-smokers women were included in this study analysis. No significant difference was observed between the two groups in regards to age, amniotic fluid index, cultural and social status, number of prior miscarriages or placenta grade. Smokers had a greater number of pregnancies and births than non-smokers, with values of 3.0 [95\%CI 3.0$11.0]$ vs. $2.0[95 \% \mathrm{CI} 1.0-5.0] \mathrm{p}=0,04 ; 1.5$ [95\% CI $0.0-$ $7.0]$ vs. $1.0[0.0-4.0] \mathrm{p}=0,04$ respectively (Table 1 ).

When the entire group of non smokers was studied, the RI in both uterine arteries (right uterine $37.3 \pm 20.0$ vs. $58.0 \pm 23.0 \mathrm{p}=0.0010$; left uterine $38.9 \pm 17.6$ vs. $56.1 \pm 19.6 \mathrm{p}=0.001)$ and the umbilical artery $(43.0 \pm$ 19.0 vs. $65.0 \pm 15.0 \mathrm{p}=0.001$ ) were higher compared to smokers. The RI in the middle cerebral artery was lower $(45.00 \pm 15.00$ vs. $36.3 \pm 21.0 \mathrm{p}=0.450)$, but, the difference was not statistically significant (Table 2 ).

When the participants were grouped according to COex levels (Group1 to Group 4), progressively higher RI values were observed for the right uterine (Group 1: $36.2 \pm 21.8$, Group 2: $46.9 \pm 20.3$, Group 3: $44.4 \pm 28.9$,
Table 1 Characteristics of the sample according to smoking habits

\begin{tabular}{lccc}
\hline & $\begin{array}{c}\text { Non smokers } \\
\mathbf{n}=\mathbf{3 4}\end{array}$ & $\begin{array}{c}\text { Smokers } \\
\mathbf{n}=\mathbf{3 0}\end{array}$ & $\mathbf{P}$ \\
\hline Characteristics & & & \\
$\quad$ Age & $27.6 \pm 6.1$ & $27.3 \pm 5.2$ & 0.82 \\
Pregnancies & 2.0 & 3.0 & 0.04 \\
& {$[1$ a 5$]$} & {$[3$ a 11$]$} & \\
Parities & 1.0 & 1.5 & 0.04 \\
Abortions & {$[0$ a 4$]$} & {$[0$ a 7$]$} & \\
AFI & 0.0 & 0.0 & 0.62 \\
Placenta grade & {$[0$ a 3$]$} & {$[0$ a 3$]$} & \\
& $14.0 \pm 2.0$ & $13.3 \pm 2.8$ & 0.21 \\
& $1(56 \%)$ & $1(70 \%)$ & 0.31 \\
{$[0$ a 2$]$} & {$[0$ a 3$]$} & \\
\hline
\end{tabular}

Data are presented as mean \pm SD or median [minimum and maximum]. AFI: amniotic fluid index. Age (years), pregnancies, abortions and parities (number), Amniotic Fluid Index(cm), Placenta grade percent type I (As classification Granumm) ${ }^{17}$. P: statistical significance.

Group 4: $66.5 \pm 17.5, \mathrm{p}<0.001)$ and left uterine arteries (Group 1: $39.5 \pm 18.9$, Group 2: $40.5 \pm 16.8$, Group 3: $52.8 \pm 19.5$, Group 4: $66.1 \pm 16.7, \mathrm{p}<0.001$ ) and the umbilical artery (Group 1: $44.5 \pm 21.3$, Group 2: $49.1 \pm 17.9$, Group 3: $61.1 \pm 13.1$, Group 4: $71.1 \pm 16.2$, $\mathrm{p}<0.001)$ as the mean COex increased. In addition, we observed lower RI values of the middle cerebral artery (Group 1: $46.4 \pm 14.3$, Group 2: $42.1 \pm 17.1$, Group 3: $47.2 \pm 19.5$, Group 4: $27.7 \pm 22.2, \mathrm{p}<0.001)$ as COex increased (Table 3).

When analyzing the increasing values of urinary cotinine in the four groups of smokers, a statistically significant progressive increase of the resistance indices for the left uterine artery $(\mathrm{p}=0.037)$ and the umbilical artery $(\mathrm{p}<0.001)$ were also identified. Although not statistically significant, the same trend was observed for the right uterine artery $\mathrm{p}=0.267$ (Table 4 ). There was, however, a decreasing trend for the RI of the middle cerebral artery related to an increasing concentration of urinary cotinine. This finding was statistically significant in the linear regression, but the significance was not maintained when adjusting for the possible confounding factors described above.

Table 2 Percentile of RI among pregnant women according to smoking habits

\begin{tabular}{cccc}
\hline & $\begin{array}{c}\text { Non smokers } \\
\mathbf{n}=\mathbf{3 4}\end{array}$ & $\begin{array}{c}\text { Smokers } \\
\mathbf{n}=\mathbf{3 0}\end{array}$ & $\mathbf{P}$ \\
\hline RI Percentile & & \\
RUA & $37.3 \pm 20.0$ & $58.0 \pm 23.0$ & 0.001 \\
LUA & $38.9 \pm 17.6$ & $56.1 \pm 19.6$ & 0.001 \\
UA & $43.0 \pm 19.0$ & $65.0 \pm 15.0$ & 0.001 \\
MCA & $45.0 \pm 15.0$ & $36.3 \pm 21.0$ & 0.450 \\
\hline
\end{tabular}

Data are presented as mean \pm SD. P: statistical significance. RUA: right uterine artery, LUA: left uterine artery,UA: umbilical artery, MCA: middle cerebral artery. Rl: vascular resistance index. 
Table 3 Percentile of RI and of birth weight between four groups according to carbon monoxide exhaled concentration

\begin{tabular}{|c|c|c|c|c|c|c|}
\hline & $\begin{array}{l}\text { COex } \\
0 \text { ppm } \\
\mathrm{n}=21\end{array}$ & $\begin{array}{c}\text { COex } \\
1-4 \text { ppm } \\
\mathrm{n}=21\end{array}$ & $\begin{array}{c}\text { COex } \\
5-9 \text { ppm } \\
n=9\end{array}$ & $\begin{array}{c}\text { COex } \\
\geq 10 \text { ppm } \\
n=13\end{array}$ & $P^{[1]}$ & $P^{[2]}$ \\
\hline \multicolumn{7}{|l|}{ RI Percentile } \\
\hline RUA & $\begin{array}{c}36.2 \pm 21.8 \\
{[10 \text { a } 90]}\end{array}$ & $\begin{array}{c}46.9 \pm 20.3 \\
{[10 \text { a } 75]}\end{array}$ & $\begin{array}{c}44.4 \pm 28.9 \\
{[10 \text { a } 90]}\end{array}$ & $\begin{array}{c}66.5 \pm 17.5 \\
{[25 \text { a } 90]}\end{array}$ & 0.003 & $<0.001$ \\
\hline LUA & $\begin{array}{c}39.3 \pm 18.7 \\
{[25 \text { a } 75]}\end{array}$ & $\begin{array}{c}40.5 \pm 16.8 \\
{[25 \text { a } 75]}\end{array}$ & $\begin{array}{c}52.8 \pm 19.5 \\
{[25 \text { a } 75]}\end{array}$ & $\begin{array}{c}66.1 \pm 16.7 \\
{[50 \text { a } 95]}\end{array}$ & $<0.001$ & $<0.001$ \\
\hline UA & $\begin{array}{c}44.5 \pm 21.3 \\
{[10 \text { a } 75]}\end{array}$ & $\begin{array}{c}49.1 \pm 17.9 \\
{[5 \text { a } 75]}\end{array}$ & $\begin{array}{c}61.1 \pm 13.1 \\
{[50 \text { a } 75]}\end{array}$ & $\begin{array}{c}71.1 \pm 16.2 \\
{[50 \text { a } 95]}\end{array}$ & 0.001 & $<0.001$ \\
\hline MCA & $\begin{array}{c}46.4 \pm 14.3 \\
{[25 \text { a } 75]}\end{array}$ & $\begin{array}{c}42.1 \pm 17.1 \\
{[5 \text { a } 75]}\end{array}$ & $\begin{array}{c}47.2 \pm 19.5 \\
{[25 \text { a } 75]}\end{array}$ & $\begin{array}{c}27.7 \pm 22.2 \\
{[5 \text { a } 75]}\end{array}$ & 0.022 & $<0.001$ \\
\hline Percentile of birth weight & $\begin{array}{c}49.05 \pm 22.7 \\
{[10 \text { a } 90]}\end{array}$ & $\begin{array}{c}49.90 \pm 25.8 \\
{[3 \text { a } 90]}\end{array}$ & $\begin{array}{c}41.2 \pm 25.3 \\
{[3 \text { a } 75]}\end{array}$ & $\begin{array}{c}25.1 \pm 16.6 \\
{[3 \text { a } 50]}\end{array}$ & 0.017 & $<0.001$ \\
\hline
\end{tabular}

Data are represented as mean \pm SD [minimum, maximum]. COex: concentration of carbon monoxide in the exhaled air, Rl: vascular resistance index, RUA: right uterine artery, LUA: left uterine artery, UA: umbilical artery, MCA: middle cerebral artery. P: statistical significance, [1]: variance analysis - ANOVA - oneway, [2]: linear tendency obtained in regression model.

There was a significant decrease $(\mathrm{p}<0.001)$ in the percentile of the fetal birth weight in relation to increased mother's COex as well as increased urinary cotinine values $(\mathrm{p}=0.007)$.

\section{Discussion}

This study showed that the resistance indices of the placental vascular bed tended to rise with a quantitative increase in tobacco smoking exposure measured by objective methods in a dose-dependent effect. As far as we know, this is the first report showing such doseeffect through objective measurements of tobacco smoking exposure.

Smoking women were classified according to progressively increasing levels of COex to look for an association of those concentrations with an increase in resistance indices. Indeed, an increase in COex levels was associated to an increase RI of the uterine and umbilical arteries and a decrease in the resistance of the middle cerebral artery. These findings were all statistically significant, even after adjusting for possible confounding factors.

When the groups were analyzed according to increasing values of urinary cotinine, another marker of tobacco exposure tested in this study, significant increases were also observed in the left uterine and umbilical arteries. The right uterine artery showed a trend towards an increased RI, however, not statistically significant. The middle cerebral artery showed a tendency towards a decreased resistance related to the increasing cotinine measurements, not statistically significant.

Smoking during pregnancy is known to influence or even determine low birth weight and it is the main preventable cause of restricted intrauterine growth and small size for gestational age [18]. Our findings are in accordance of previous reports, showing that as a

Table 4 Percentile of RI and of birth weight between four groups according to urinary cotinine levels

\begin{tabular}{|c|c|c|c|c|c|c|}
\hline & $\begin{array}{c}\text { Cotinine } \\
0 \\
\mathrm{ng} / \mathrm{mL} \\
\mathrm{n}=30\end{array}$ & $\begin{array}{c}\text { Cotinine } \\
<50 \mathrm{ng} / \mathrm{mL} \\
n=10\end{array}$ & $\begin{array}{c}\text { Cotinine } \\
50-500 \mathrm{ng} / \mathrm{mL} \\
\mathrm{n}=14\end{array}$ & $\begin{array}{c}\text { Cotinine } \\
>500 \mathrm{ng} / \mathrm{mL} \\
\mathrm{n}=10\end{array}$ & $P^{[1]}$ & $P^{[2]}$ \\
\hline \multicolumn{7}{|l|}{ RI Percentile } \\
\hline RUA & $\begin{array}{c}42.8 \pm 22.8 \\
{[10 \text { a } 90]}\end{array}$ & $\begin{array}{c}40.0 \pm 25.7 \\
{[10 \text { a } 90]}\end{array}$ & $\begin{array}{c}55.3 \pm 23.5 \\
{[10 \text { a } 90]}\end{array}$ & $\begin{array}{c}22.9 \pm 22.9 \\
{[25 \text { a } 75]}\end{array}$ & 0.201 & 0.267 \\
\hline LUA & $\begin{array}{c}41.1 \pm 20.8 \\
{[25 \text { a } 95]}\end{array}$ & $\begin{array}{c}42.5 \pm 20.6 \\
{[25 \text { a } 75]}\end{array}$ & $\begin{array}{c}58.9 \pm 15.8 \\
{[25 \text { a } 75]}\end{array}$ & $\begin{array}{c}52.5 \pm 18.4 \\
{[25 \text { a } 75]}\end{array}$ & 0.033 & 0.037 \\
\hline UA & $\begin{array}{c}46.8 \pm 20.1 \\
{[5 \text { a } 75]}\end{array}$ & $\begin{array}{c}46.0 \pm 21.0 \\
{[10 \text { a } 75]}\end{array}$ & $\begin{array}{c}63.5 \pm 14.6 \\
{[50 \text { a } 90]}\end{array}$ & $\begin{array}{c}68.5 \pm 17.3 \\
{[50 \text { a } 95]}\end{array}$ & 0.003 & 0.001 \\
\hline MCA & $\begin{array}{c}45.3 \pm 15.7 \\
{[5 \text { a } 75]}\end{array}$ & $\begin{array}{c}42.5 \pm 16.8 \\
{[25 \text { a } 75]}\end{array}$ & $\begin{array}{c}36.8 \pm 21.8 \\
{[5 \text { a } 75]}\end{array}$ & $\begin{array}{c}34.5 \pm 23.8 \\
{[5 \text { a } 75]}\end{array}$ & 0.321 & 0.14 \\
\hline Percentile of birth weight & $\begin{array}{c}45.6 \pm 21.5 \\
{[3 \text { a } 90]}\end{array}$ & $\begin{array}{c}62.4 \pm 24.4 \\
{[25 \text { a } 90]}\end{array}$ & $\begin{array}{c}36.6 \pm 24.0 \\
{[3 \text { a } 90]}\end{array}$ & $\begin{array}{c}27.1 \pm 22.8 \\
{[3 \text { a } 75]}\end{array}$ & 0.006 & 0.007 \\
\hline
\end{tabular}

Data are represented as mean \pm SD [minimum, maximum]. RI: vascular resistance index, RUA: right uterine artery, LUA: left uterine artery, UA: umbilical artery, MCA: middle cerebral artery. P: statistical significance, [1]: variance analysis - ANOVA - oneway, [2]: adjusted for age, number of pregnancies and AFI in ANCOVA model. 
consequence of the increase in resistance indices, the decrease amount of blood and oxygen transported to the fetus resulted in lower weights of the newborns.

This study contributes to those reports showing that it is probably a dose-dependent effect. We found that decreased birth weights correlated with increase in tobacco smoking exposure, confirmed by both exposure methods, urinary cotinine and COex.

A pattern of maternal-fetal perfusion with characteristics of chronic hypoxia among the pregnant smokers was observed. Those findings were similar to the centralization phenomenon [19], with an increase in the RI of the umbilical artery and a decrease in RI of the middle cerebral artery. Thus, we infer that the fetus of a smoking mother, as a consequence of the decreased placental blood flow and possible tissue hypoxia, compensates with tendency towards centralization of the blood flow.

Although the details of these circulatory adjustments and their mechanisms are incomplete, it is likely that when the partial pressure of $\mathrm{O}_{2}$ decreases and that of $\mathrm{CO}_{2}$ increases above a certain level, the aortic and carotid chemoreceptors are activated. This probably is the mechanism that regulates the central vasodilatory response to guarantee adequate oxygenation to the fetal brain [20].

Prior studies $[6,19,21,22]$ already studied the repercussions of smoking on maternal-fetal flow, but all have used patients' self-report to quantify tobacco smoking exposure. As mentioned previously, data reported by smoking patients are not always reliable, what might justify the heterogeneity of the results found in those studies [23].

Albuquerque and colleagues [19] compared 74 pregnant smokers with 69 controls, classifying then according to smoking status as informed by the patients. They concluded that chronic maternal smoking was associated with the increasing resistance of the uterine, umbilical and fetal middle cerebral arteries. Other studies [20,21] evaluated the cigarette acute effects. Kimya et al. [6] studied 22 pregnant smokers and 21 non-smokers by measuring Pulsatility Index, Resistance Index and Systole/Diastole of the uterine and umbilical before and after smoking a cigarette default. They found no significant change in the Doppler that could be attributed to the acute effect of cigarette smoking, but all indices were significantly higher in the smoking group compared with the control group both before and after cigarette smoking. They conclude that chronic smoking caused an increase in vascular resistance of the placenta and umbilical cord.

One of the strengths of this study is that the smoking status of the patients were confirmed by biochemical quantitative measurements (concentration of exhaled $\mathrm{CO}$ and of cotinine in a urine sample), showing a possible dose-effect of tobacco smoking exposure on maternal-fetal blood perfusion.

Our results may be used as a tool for helping pregnant smokers to stop or at least to decrease their tobacco exposure by emphasizing that the risks to the fetus occur in a dose-dependent manner. Our objective data demonstrate that a higher smoking level results in greater hemodynamic effects on the fetus. These effects culminate in growth restriction that may have multiple effects throughout the life of children.

\section{Conclusions}

In this study, using Doppler velocimetry in uterine, umbilical and middle cerebral arteries flow, changes in resistance indeces were detected comparing smoking to non smoking pregnant women. A dose-dependent effect in placental blood flow was found such that resistance indices increased in accordance with increasing levels of tobacco smoking exposure.

In addition, we found a decrease in fetal birth weight that also correlated with an increase in measurements of COex and urinary cotinine.

\section{Acknowledgements}

This study received no grants.

\section{Author details}

'Obstetrics, Sao Lucas Hospital da Pontificia Universidade Catolica do Rio Grande do Sul,of Rio Grande do Sul, Porto Alegre, Brazil. ${ }^{2}$ Pharmacy student of the Pontificia Universidade Catolica do Rio Grande do Sul, Porto Alegre, Brazil. ${ }^{3}$ Pulmonary Disease, Sao Lucas Hospital, School of Medicine, Pontificia Universidade Catolica do Rio Grande do Sul , Brazil.

\section{Authors' contributions}

JDBM: physician, principal investigator and responsible writing the first draft of the paper. PVM: physician, co-investigator, responsible for the patients. GOP: chemistry student, responsible for the biochemical techniques. JMC: physician, responsible for the statistical analyses and for writing and reviewing the manuscript. All authors read and approved the final manuscript.

\section{Competing interests}

The authors declare that they have no competing interests.

Received: 21 January 2010 Accepted: 31 March 2011

Published: 31 March 2011

\section{References}

1. Walsh RA, Lowe JB, Hopkins PJ: Quitting smoking in pregnancy. Med J Aust 2001, 175:320-3.

2. Jakab Z: Smoking and pregnancy. Acta Obstet Gynecol Scand 2010, 89:416-7.

3. Braun JM, Daniels JL, Kalkbrenner A, Zimmerman J, Nicholas JS: The effect of maternal smoking during pregnancy on intellectual disabilities among 8-year-old children. Paediatr Perinat Epidemiol 2009, 23:482-91.

4. Kyu HH, Georgiades K, Boyle MH: Maternal smoking, biofuel smoke exposure and child height-for-age in seven developing countries. Int J Epidemiol 2009, 38:1342-50.

5. Jaakkola JJ, Gissler M: Maternal smoking in pregnancy, fetal development, and childhood asthma. Am J Public Health 2004, 94:136-40.

6. Kimya Y, Cengiz C, Ozan H, Kolsal N: Acute effects of maternal smoking on the uterine and umbilical artery blood velocity waveforms. J Matern Fetal Investig 1998, 8:79-81. 
7. Murray RP, Connett JE, Lauger GG, et al: Error in smoking measures: effects of intervention on relations of cotinine and carbon monoxide to self-reported smoking. The Lung Health Study Research Group. Am J Public Health 1993, 83:1251-1257.

8. Gadomski A, Adams L, Tallman N, Krupa N, Jenkins P: Effectiveness of a Combined Prenatal and Postpartum Smoking Cessation Program. Matern Child Health J 2010, Jan 21 Published online.

9. Aranda Regules JM, Mateos Vilchez P, Gonzalez Villalba A, Sanchez F, et al: Validity of smoking measurements during pregnancy: specificity, sensitivity and cut-off points. Rev Esp Salud Publica 2008, 82:535-45.

10. Fiore MC, Jaén RC, Baker TB, et al: Treating tobacco use and dependence:2008 up date. AHCPR Supported Guide and Guidelines.

11. Middleton ET, Morice AH: Breath carbon monoxide as an indication of smoking habit. Chest 2000, 117:758-763.

12. Chatkin JM, Abreu CM, Haggstram FM, et al: Exhaled CO: is 10 PPM a reliable threshold value to confirm current smoking? Am J Respir Crit Care Med 2002, 165:19s.

13. Laranjeira R, Pillon S, Dunn J: Environmental tobacco smoke exposure among non-smoking waiters: measurement of expired carbon monoxide levels. São Paulo Med J 2000, 118:89-92.

14. Santos UP, Gannam S, Abe JM, et al: Use of breath carbon monoxide as an indicator of smoking status (Emprego da determinação de monóxido de carbono no ar exalado para a detecção do consumo de tabaco). J Pneumol 2001, 27:7-12.

15. Chatkin J, Fritscher L, de Abreu C, Cavalet-Blanco D, Chatkin G, Wagner M, et al: Exhaled carbon monoxide as a marker for evaluating smoking abstinence in a Brazilian population sample. Prim Care Respir J 2007, 16:36-40.

16. Petersen GO, Leite CE, Chatkin JM, Thiesen FV: Cotinine as a biomarker of tobacco exposure: development of HPLC method and comparison of matrices. J Sep Sci 2010, 33:516-21.

17. Pastore A: Ultra-sonografia em ginecologia e obstetrícia (Ultrasound in obstetrics and gynecology). Rio de Janeiro, Brazil: Revinter, 1 2003, 1-290.

18. Aagaard-Tillery KM, Porter TF, Lane RH, Varner MW, Lacoursiere DY: In utero tobacco exposure is associated with modified effects of maternal factors on fetal growth. Am J Obstet Gynecol 2008, 198:56.e1-56.e4.

19. Albuquerque CA, Smith KR, Johnson C, Chao R, Harding R: Influence of maternal tobacco smoking during pregnancy on uterine, umbilical and fetal cerebral artery blood flows. Early Hum Dev 2004, 80:31-42.

20. Dawes GS, Lewis BV, Milligan JE, Roach MR, Talner NS: Vasomotor responses in the hind limbs of foetal and new-born lambs to asphyxia and aortic chemoreceptor stimulation. J Physiol 1968, 195:55-81.

21. Castro LC, Allen R, Ogunyemi D, Roll K, Platt LD: Cigarette smoking during pregnancy: acute effects on uterine flow velocity waveforms. Obstet Gynecol 1993, 81:551-5.

22. Abdul-Khaliq H, Segerer H, Luck W, Obladen M: Increased cerebral blood flow velocities in newborn infants of smoking mothers. Eur J Pediatr 1993, 152:232-5.

23. Caraballo RS, Giovino GA, Pechacek TF: Self-reported cigarette smoking vs. serum cotinine among U.S. adolescents. Nicotine Tob Res 2004, 6:19-25.

\section{Pre-publication history}

The pre-publication history for this paper can be accessed here: http://www.biomedcentral.com/1471-2393/11/24/prepub

doi:10.1186/1471-2393-11-24

Cite this article as: de B Machado et al:: Quantitative effects of tobacco smoking exposure on the maternal-fetal circulation. BMC Pregnancy and Childbirth 2011 11:24

\section{Submit your next manuscript to BioMed Central and take full advantage of:}

- Convenient online submission

- Thorough peer review

- No space constraints or color figure charges

- Immediate publication on acceptance

- Inclusion in PubMed, CAS, Scopus and Google Scholar

- Research which is freely available for redistribution

Submit your manuscript at www.biomedcentral.com/submit
Biomed Central 